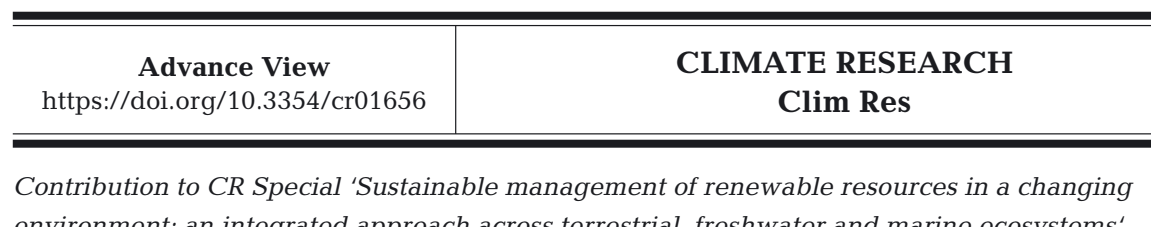

environment: an integrated approach across terrestrial, freshwater and marine ecosystems'

\title{
REVIEW
}

\section{Population responses to harvesting in fluctuating environments}

\author{
Aline Magdalena Lee ${ }^{1, *}$, Javier Jarillo ${ }^{2}$, Bart Peeters ${ }^{1}$, Brage Bremset Hansen ${ }^{1}$, \\ Francisco J. Cao-García ${ }^{3,4}$, Bernt-Erik Sæther ${ }^{1}$, Steinar Engen ${ }^{5}$
}

${ }^{1}$ Centre for Biodiversity Dynamics, Department of Biology, Norwegian University of Science and Technology, 7491 Trondheim, Norway

${ }^{2}$ Research Unit of Environmental and Evolutionary Biology, Namur Institute of Complex Systems, and Institute of Life, Earth, and Environment, University of Namur, 5000 Namur, Belgium

${ }^{3}$ Departamento de Estructura de la Materia, Física Térmica y Electrónica, Universidad Complutense de Madrid, 28040 Madrid, Spain

${ }^{4}$ Instituto Madrileño de Estudios Avanzados en Nanociencia (IMDEA-Nanociencia), 28049 Madrid, Spain

${ }^{5}$ Centre for Biodiversity Dynamics, Department of Mathematical Sciences, Norwegian University of Science and Technology, 7491 Trondheim, Norway

\begin{abstract}
Achieving sustainable harvesting of natural populations depends on our ability to predict population responses to the combined effects of harvesting and environmental fluctuations while accounting for other internal and external factors that influence population dynamics in time and space. Here, we review recent research showing how spatial patterns and interspecific interactions can influence population responses to harvesting in fluctuating environments. We highlight several pathways through which harvesting can, often inadvertently, influence the dynamics and resilience to environmental fluctuations of both harvested and surrounding non-harvested populations and species. For instance, spatial models have shown that harvesting is expected to influence the spatial synchrony of population fluctuations, both of the harvested species and its competitors, predators and prey, with implications for population extinction risk. Dispersal and interspecific interactions can cause responses to harvesting in areas and species that are not themselves harvested. Harvesting that selectively targets certain groups of individuals, either intentionally or through for example spatially biased harvesting, can amplify environmentally induced population fluctuations by biasing the population structure towards individuals that are more sensitive to environmental variation. On the other hand, harvesting can in some cases buffer populations against the densitydependent effects of harsh climatic conditions, which are probably more common than previously acknowledged. Recent advances in modeling are providing new predictions that are highly relevant under global warming and now need to be tested empirically. We discuss how knowledge of these pathways can be used to increase the sustainability of harvesting.
\end{abstract}

KEY WORDS: Climate change $\cdot$ Environmental stochasticity $\cdot$ Hunting $\cdot$ Fisheries $\cdot$ Multi-species systems $\cdot$ Population structure

\section{INTRODUCTION}

Sustainable harvesting of natural populations requires an in-depth understanding of population dynamics. Predictions of population responses to differ-

${ }^{*}$ Corresponding author: lee@alumni.ntnu.no ent harvesting pressures and strategies must be based on knowledge of the natural processes influencing population dynamics and how harvesting may influence these processes (Jonzen et al. 2003, Anderson et al. 2008). It is well known that environ-

() The authors 2021. Open Access under Creative Commons by Attribution Licence. Use, distribution and reproduction are unrestricted. Authors and original publication must be credited. 
mental stochasticity, i.e. random fluctuations in the environment affecting all or groups of individuals similarly, plays a major role in the dynamics of most natural populations (den Boer 1981, Sæther \& Engen 2002), driving fluctuations in population abundance (Sæther 1997) and generally causing decreased longterm population growth (Tuljapurkar 1982). In the coming years, climate warming is predicted to cause more variable weather (IPCC 2013) and thus greater environmental stochasticity, challenging the resilience of populations, with the risk of triggering extinctions (Engen et al. 2002, Crespo \& Cao-García preprint https://arxiv.org/abs/2008.09398). In addition to influencing the dynamics of populations directly, environmental stochasticity adds uncertainty to predictions of these dynamics, with the result that harvesting in the presence of environmental stochasticity generally needs to be more conservative to be sustainable than what would be predicted from deterministic models (Beddington \& May 1977, May et al. 1978, Lande et al. 1995, 1997) to avoid unexpected population crashes.

Predicting population responses to harvesting in fluctuating environments is complicated by many of internal and external factors affecting population dynamics in time and space. For one, individuals within a population vary in age and traits, and harvesting is often non-random with respect to at least some of these traits (Apollonio et al. 2010, Kuparinen \& Festa-Bianchet 2017). It is now well known that this can have substantial influences on harvested populations (Bunnefeld et al. 2011, Engen et al. 2014). For example, size-selective harvesting in fish has been shown to affect growth rates and body size (Swain et al. 2007), age at maturity and reproductive allocation (Heino et al. 2015), potentially reducing overall reproductive rates and population viability (Hutchings 2005, Venturelli et al. 2009). Selective harvesting can also have substantial impacts on demographic structure, such as age and sex structure (Langvatn \& Loison 1999). This may impact population dynamics (Stubberud et al. 2019, Sæther et al. 2001,2003 ) since individuals of different ages contribute differently to future population growth (Sæther \& Bakke 2000, Hauser et al. 2006). Therefore, different aspects of population structure should be considered when developing harvesting models and strategies for structured populations (Beddington 1974, Milner et al. 2007).

Furthermore, the environments that natural populations inhabit are not spatially homogenous, but rather tend to exhibit some level of spatial heterogeneity and structure. This means that the spatial location of individuals influences what environmental conditions they experience, with implications for the spatial distribution of individuals within and among populations. There is considerable evidence that harvesting can have important effects on the spatial structure of populations (Hsieh et al. 2008, Frank et al. 2016, Le Moullec et al. 2019). However, there has been relatively little focus on the spatial aspects of optimal harvesting theory for animal populations, with the exception of the design and function of marine reserves (Neubert 2003, Costello \& Polasky 2008). In particular, harvesting effects on population synchrony (and vice versa) have only very recently been considered. Shared environmental fluctuations can cause synchronized population fluctuations, with populations that are near each other showing more synchronous dynamics than those that are further apart (Moran 1953, Koenig 2002, Walter et al. 2017). This pattern has been observed in a wide range of taxa (Liebhold et al. 2004, Ranta et al. 2006), and synchronized population dynamics across large areas have been shown to increase the global extinction risk of populations (Heino et al. 1997, Earn et al. 2000, Engen et al. 2002) as well as influencing the propagation of invasive species (Giometto et al. 2017) and the spread of diseases (Kausrud et al. 2007). Harvesting strategies that amplify population synchrony might therefore be less sustainable.

Traditionally, harvesting models have been developed for single species of interest. However, in natural systems, species interact with each other through shared resources, disturbance competition, predator-prey interactions and mutualism. Thus, harvestinduced changes in the dynamics of one species can influence the dynamics of other species in the system (Pauly et al. 1998, Smith et al. 2011). In fact, it has been shown that using the common harvesting strategy of aiming for single-species maximum sustainable yield (Schaefer 1991) will lead to extinction of species in most marine ecosystems (Legović et al. 2010). Multispecies models that consider interspecific interactions therefore perform better than singlespecies models of the same systems (Kinzey \& Punt 2009). Thus, to achieve sustainable harvesting, we must consider how species interactions and interspecific density effects influence population dynamics. In this multispecies context, spatial dynamics may be especially important because co-occurrence in space and time is a prerequisite for many types of species interactions, and species interactions also modify the distribution and movement of species and their responses to climate change (Hillyer \& Silman 2010, Urban et al. 2013, Godsoe et al. 2015). 
Population dynamic responses to harvesting depend not only on the harvesting itself but also on how it relates to environmental fluctuations and climate. Distinguishing effects of environmental variation and warming from effects of harvesting itself is often difficult, particularly because they interact such that climate can cause harvesting schemes to have unexpected outcomes, and harvesting can increase populations' sensitivity to environmental changes (Planque et al. 2010). In the coming years, the climate is expected to continue becoming warmer and more variable, with more frequent extreme events (IPCC 2013). Because climate change can influence spatial distributions and structure (Chen et al. 2011), dispersal and connectivity (Munday et al. 2009, Jenkins et al. 2016, Evans et al. 2019), population synchrony (Hansen et al. 2020) and species interactions (Lord et al. 2017, Boukal et al. 2019), this adds to the challenge of developing sustainable harvesting strategies. Both theoretical and empirical work has long suggested that, in density-regulated populations, the impacts of environmental stochasticity on population dynamics depend on characteristics of the fluctuations in population density (May et al. 1978, Coulson 2001), which, in turn, directly influence the sustainability of different harvesting strategies (Sæther et al. 1996). Such interactions between climate and density effects could cause harvesting to either amplify or dampen natural population fluctuations and should be studied in greater detail (Gamelon et al. 2019).

In this study, we review recent research showing how spatial patterns and species interactions are expected to influence population responses to harvesting in fluctuating environments. We identify several pathways through which harvesting can, often inadvertently, influence the demography and resilience to environmental fluctuations of both harvested and surrounding non-harvested populations and species (Fig. 1), and discuss how this knowledge can be used to improve the sustainability of harvesting.

\section{INFLUENCE OF SPATIAL PATTERNS ON RESPONSES TO HARVESTING}

Populations are not evenly distributed across space but are influenced by the spatial structure of their environment (Planque et al. 2011), and spatial processes play an important role in population dynamics. For example, theory has shown that single location populations experiencing an Allee effect (i.e. negative growth rate at low densities; Allee 1949) always eventually go extinct in the presence of envi- ronmental fluctuations (Dennis 2002). However, when the spatial dimension is added, this is no longer the case (Dennis et al. 2016, Crespo \& Cao-García preprint https://arxiv.org/abs/2008.09398). Dispersal of individuals can help regions to recover from population depletion through immigration of individuals from non-depleted regions (Kuussaari et al. 1998, Péron et al. 2012), sometimes termed the rescue effect (Brown \& Kodricbrown 1977). In this way, dispersal between different locations increases the resilience of populations to weather and other environmental fluctuations, such that the amplitude of environmental fluctuations above which populations go extinct increases when the dispersal rate or the dispersal distance increases (Crespo \& Cao-García preprint https://arxiv.org/abs/2008.09398). Thus, spatial considerations play a key role in the viability of populations in the presence of environmental fluctuations. Influences of different harvesting strategies on the spatial distribution of populations could therefore be expected to have major impacts on their sustainability, and thus incorporating space into harvesting models is important.

Simple harvesting models often assume proportional or constant effort harvesting, in which the harvest offtake is directly proportional to the population abundance at any point in space, but in practice, harvesting is often regulated by quotas that operate on coarser scales and are less tightly correlated with local abundances (Fryxell et al. 2010). The spatial distribution of such harvesting is seldom directly proportional to the spatial distribution of the harvested species and is often concentrated on smaller areas of a population's range. This can be a direct consequence of management policies, such as for populations that experience different harvesting pressures because they are spread across more than one hunting district or country (Apollonio et al. 2010), or populations that exist partly within and partly outside protected areas (Moland et al. 2013, Poisson et al. 2020). Harvesting or management units may vary greatly in area size and habitat quality, while distance, connectivity and barriers between hunting units may further determine spatiotemporal variation in population density and structure (Turgeon \& Kramer 2012, Edelhoff et al. 2020). In addition, realized harvesting pressures can vary greatly, both among and within management units, in ways not regulated by quotas and policies. For example, Peeters et al. (2021, this Special) showed that realized harvest effort for Svalbard reindeer Rangifer tarandus platyrhynchus differed among hunting units and was highly concentrated along the coast- 


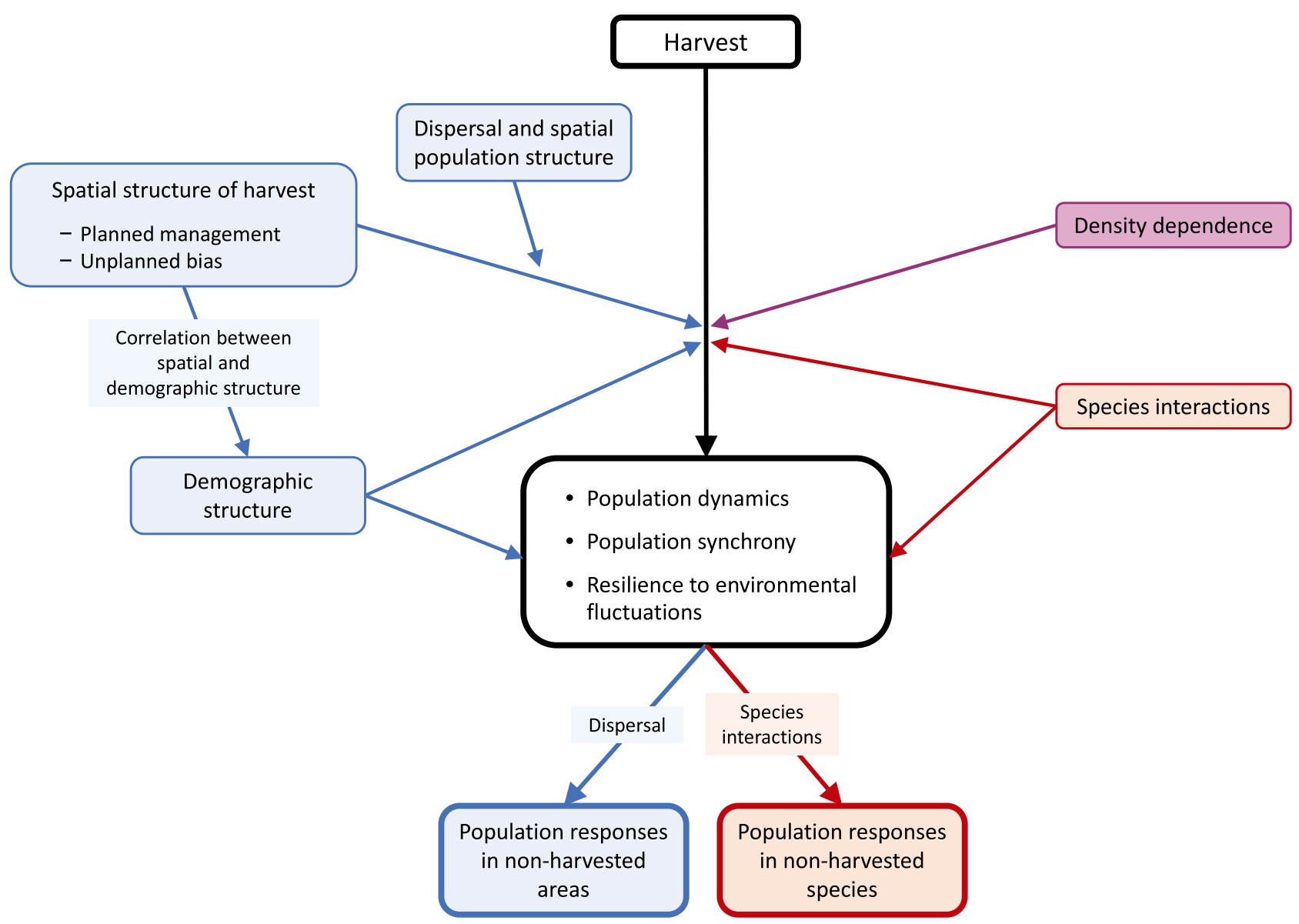

Fig. 1. Population responses to harvesting depend on spatial patterns, species interactions and density dependence. This figure illustrates some of the main pathways discussed in this study through which spatial patterns (blue; see Section 2), species interactions (red; Section 3) and density dependence (purple; Section 4) alter harvesting effects on population dynamics, synchrony and resilience to environmental fluctuations. Arrows between boxes show effects of the factor or process in one box on the other. Arrows aimed at other arrows show how factors or processes modify the effects represented by the receiving arrows. Labels on arrows describe mechanisms through which the effects represented by the arrows function. Note that this is not a complete representation of possible or realized pathways, but a simplified overview of main points discussed in the text

line, despite population densities generally being higher inland, because hunters used motorized boats as a mode of transportation. Such harvesting bias can substantially alter population dynamics, particularly when dispersal among units is low (Péron et al. 2012).

Dispersal is a key factor in determining how spatial structure in harvesting regimes influences population dynamics. High levels of dispersal between areas will tend to homogenize population dynamics, weakening any spatial structure caused by harvesting (Lande et al. 1998). Both constant dispersal rates and positive density-dependent dispersal rates, which are common in nature (Rodrigues \& Johnstone 2014), have this homogenizing effect, because more individuals disperse from areas with high abundances. Dispersal could thus lessen the impact on heavily harvested areas through immigration of individuals from areas with less harvesting, thus reducing the risk of local extinction (Fogarty \& Botsford 2007, Naranjo \& Bodmer 2007). This effect of dispersal can be exploited by setting up patchworks of protected and non-protected areas for harvested populations (McCullough 1996, Mockrin \& Redford 2011). The protected areas, or no-take zones, can increase the sustainability of harvesting if the increased survival and reproduction within these areas, and subsequent dispersal of individuals to non-protected areas, is great enough to help offset the harvesting mortality (Fogarty \& Botsford 2007). No-take areas are particularly common in marine management and can increase both sustainability and yield (Halpern 2003, Cabral et al. 2020). Such protected areas are expected to be the most successful when each area is large enough to maintain a viable population, but 
small enough to promote rapid dispersal of individuals to surrounding harvested areas as local populations grow (McCullough 1996). On the other hand, if a heavily harvested area becomes a sink population, with a steady stream of individuals from other areas moving into the higher mortality area, this could have detrimental effects on the full metapopulation, increasing global extinction risk (Novaro et al. 2005). Knowledge of dispersal pathways and population connectivity is thus a crucial prerequisite for successful harvesting management (Brook \& Whitehead 2005, Fogarty \& Botsford 2007, Costello \& Polasky 2008).

Climate change and habitat loss are causing species distributions to shift and contract (Chen et al. 2011, VanDerWal et al. 2013, Herrera-R et al. 2020), and species are encountering new dispersal barriers (Jenkins et al. 2016, Peeters et al. 2020). Such changes to dispersal pathways and spatial structure can alter the effects of harvesting regimes by, for instance, weakening the connection between unharvested and harvested areas and thus weakening the rescue effect from dispersal, or causing populations to move out of protected areas (Monzón et al. 2011). Range contractions can increase the danger of overharvesting by allowing local densities of a species to stay high enough to allow profitable harvesting, even as total numbers are rapidly declining (Burgess et al. 2017). This highlights the need for dynamic management regimes that can be adjusted as the underlying conditions change.

In many species, the spatial distribution of individuals is influenced by their age, sex, breeding status, personality or other traits (Loe et al. 2006, Morita et al. 2010, Campioni et al. 2012, Mourier et al. 2013). Accordingly, spatial patterns in harvesting pressure can cause different levels of harvest mortality in different groups. For example, a recent study on moose showed that individuals that spent more time in open grasslands were more likely to be shot, but these individuals also produced more and heavier calves (Ofstad et al. 2020). In white-tailed deer Odocoileus virginianus, habitat selection was found to be sexand age-specific, with differences in hunting mortality risk between different areas (Haus et al. 2020). Over time, such spatial structure in harvest mortality can also cause changes in habitat use that can further influence population dynamics (Milner et al. 2007, Frank et al. 2017, Lefebvre et al. 2017). Knowledge of spatial structure and habitat use can improve management and harvesting strategies, for example by avoiding harvest in areas used by age classes of high value to the population (Edwards \& Plagányi 2011) or for reproduction (Ellis \& Powers 2012, Grüss \& Robin- son 2015), and supporting compensatory immigration mitigating the recovery of depleted populations (Stoner et al. 2006, Turgeon \& Kramer 2012).

Spatially extended harvesting also affects the spatial synchrony of population fluctuations. Theoretical models have shown that proportional harvesting, i.e. harvesting the same fraction of the local population at each locality, increases the spatial scale of population synchrony by reducing the effects of density regulation (Engen et al. 2018a,b, Jarillo et al. 2018). On the other hand, increasing harvesting in high-abundance regions leads to decoupling between the regions, reducing the spatial scale of population synchrony (Engen et al. 2018a). Thus, choosing among different spatial structures in harvesting strategies can have major impacts on the spatial patterns and synchrony of population dynamics. Although these theoretical results still need to be tested empirically, the temporal and spatial scales of fishing mortality are sufficient to drive population synchrony (Frank et al. 2016), and increased synchrony in growth caused by harvesting has been demonstrated in a recent study of New Zealand fisheries (Morrongiello et al. 2021). Because synchrony in population dynamics increases the risk of simultaneous declines in population size over large areas, and thus global extinction risk, these results demonstrate that the commonly recommended strategy of spatially proportional harvesting could increase population extinction risk more than previously predicted. This aspect of spatial harvesting strategies has only recently received attention, but these results indicate that spatial synchrony should be considered when comparing different harvesting strategies. In addition, it has been shown that increased spatial correlation in abundance can be an important early-warning signal of shifts to alternative stable states in ecosystems, indicating that a greater focus on spatial correlation could help us to avoid catastrophic effects of overharvesting in changing climate conditions (Dakos et al. 2010).

Stochastic modeling of spatial population dynamics and harvesting is quite challenging because such models must account not only for intrinsic population dynamics but also dispersal of individuals and spatial patterns of environmental stochasticity. However, such models provide a valuable opportunity to incorporate spatial aspects into evaluation of harvest strategies. Engen et al. (2018b) developed such a model for 2 age classes with density dependence within the juvenile class and showed how the optimal strategy for maximizing mean annual yield depends on the relative economic value of the 2 age classes. When one age class is much more valuable than the other, 
the optimal strategy is to harvest only that age class. As environmental stochasticity increases, the range of relative economic values for which it is optimal to harvest both age classes also increases, while optimal harvesting rates decrease. Models of this type could be used to inform optimal harvesting strategies in many other spatial contexts and will likely be important for future harvesting theory.

\section{INFLUENCE OF SPECIES INTERACTIONS ON RESPONSES TO HARVESTING}

Harvested populations do not live in isolation but are embedded in natural communities in which they interact with other species. This complicates the process of predicting population responses to harvesting because changes in the abundance or dynamics of one species can trigger complex feedback loops and indirect effects on both the harvested and surrounding species. Management and harvest strategies based on single-species models can have dramatic consequences on multi-species systems, including species extinctions (Legović \& Geček 2010, Legović et al. 2010, Tromeur \& Doyen 2019). For this reason, more ecosystem-based management approaches have been proposed. Ideally, an ecosystem-based management approach should recognize the full array of interactions in an ecosystem, including humans, instead of considering single-species or ecosystem services in isolation (Katsanevakis et al. 2011). Ecosystem-based approaches are now broadly accepted as crucial for marine conservation and resource management (Levin et al. 2009), and several frameworks for multi-species models have been suggested as tools to improve predictions of harvest effects in an ecosystem context (Plagányi et al. 2014). However, predicting the impacts of harvesting requires an understanding of the interspecific interactions in a system, and studies have shown that there are multiple ways in which these can influence the outcomes of harvesting.

Interspecific interactions can exacerbate the mortality caused by harvesting. For example, Gehr et al. (2018) found that hunter avoidance behavior in roe deer Capreolus capreolus exposed them to greater risk of predation by Eurasian lynx Lynx lynx. The lynx, in turn, responded by increasing predation on deer, causing superadditive hunting mortality. The classical examples of harvesting impact in systems of interacting species are from systems in which removal of a top predator initiates a trophic cascade, such as when overharvesting of sea otters Enhydra lutris in Alaska caused explosive growth of their main prey, sea urchins Strongylocentrotus spp. This led to overgrazing of kelp, and consequently impacted the numerous species that depend on the habitat created by kelp forests (Estes \& Duggins 1995, Silliman \& Angelini 2012). In this way, harvesting of a single species can have serious impacts on species that are not themselves harvested, destabilize whole communities and seriously reduce their resilience to climate change (Chaverra et al. 2019). Moreover, dispersal or migration can extend the interspecific effects of harvest to areas that are not harvested. For example, Anderwald et al. (2015) showed that harvesting of migratory red deer Cervus elaphus outside a national park had a positive effect on ibex Capra ibex and chamois Rupicapra rupicapra within the park by reducing the number of red deer migrating back into the park, thereby lessening interspecific competition. Thus, spatial and interspecific effects need to be considered together to fully understand potential impacts on harvesting.

Predicting the overall outcome of harvesting becomes even more challenging when multiple interacting species are harvested. In such cases, the impact of a given harvest rate on one species can depend on the harvest rates of other species, since these rates influence the abundance of the first species' competitors, predators or prey (Dunn et al. 2017). It is a well-known principle that simultaneous harvesting of a predator and its prey increases the proportion of prey at equilibrium (Volterra 1928, Weisberg \& Reisman 2008). However, the overall impact of harvesting becomes more complicated to predict as the number of target species increases, and appropriate reference points for harvesting will depend on both species interactions and environmental effects (Kumar et al. 2017). This is particularly relevant in fisheries management, since marine systems typically consist of multiple harvested species. The realization that it is not generally feasible to maximize the yield from all species simultaneously without causing extinctions (Thorpe 2019) has caused increased focus on the ecosystem perspective for harvest management, and many fisheries models now aim to account for at least some interspecific interactions (Plagányi 2007); however, developing sustainable harvesting strategies for multispecies systems is still challenging (Fogarty 2014, Law et al. 2016, Thorpe 2019).

Species that share the same environment could be expected to display similar patterns of population synchrony. However, Marquez et al. (2019) showed that population synchrony varied among fish species 
within the Barents Sea, with species that live longer generally being synchronized over larger areas, potentially because such species tend to show weaker density regulation (Lande et al. 1999, Herrando-Pérez et al. 2012). On the other hand, both theoretical (Ripa \& Ranta 2007) and empirical (Kent et al. 2007, Haynes et al. 2009) studies have revealed that spatial population synchrony can be transferred between species via direct or indirect interspecific interactions. For example, it is well known that predation by mobile predators can drive spatial synchrony in prey populations (Ims 1990, Ims \& Andreassen 2000, Liebhold et al. 2004). As mentioned previously, spatial synchrony is known to influence global extinction risk (Heino et al. 1997, Earn et al. 2000); patterns of spatial synchrony are expected to change under climate warming (Hansen et al. 2020); and harvesting affects spatial synchrony (Engen et al. 2018a,b, Jarillo et al. 2018). Combined, these observations highlight the importance of understanding the links between harvesting, environmental fluctuations, interspecific interactions and spatial population synchrony of species within an ecosystem for our ability to evaluate potential ecosystem responses to harvesting.

Recent theoretical work has shown that competition between 2 species can increase or decrease the spatial population synchrony of each of the competitors (Jarillo et al. 2018, Lee et al. 2020) depending on the correlation between the environmental noise affecting the competitors, their growth rates, dispersal dynamics and intraspecific and interspecific competition strengths. The spatial scale of the synchrony between competing populations is closely related to the spatial scale of the within-species synchrony (Lee et al. 2020). In these competitive systems, the proportional harvesting of one of the competitors increases the spatial scale of population synchrony of the harvested species, but also of the unharvested competitor (Jarillo et al. 2018).

Theory predicts that, in bottom-up regulated food webs, spatial population synchrony of species should increase with trophic level, so any predator would have a larger spatial scale of population synchrony than its prey (Jarillo et al. 2020). This result has been experimentally observed in bacterial communities (Kent et al. 2007). In such bottom-up regulated predator-prey systems, proportional harvesting of the prey increases the spatial scale of population synchrony of its predator while proportional harvesting of the predator reduces the scale of synchrony of its prey (Jarillo et al. 2020). In general, increases in the spatial scale of population synchrony follow the directional propagation of fluctuations through food webs. Thus, depending on the structure and functioning of a food web, harvesting any species can alter the spatial scaling of all species across the food web, with potential implications for extinction risk. Harvesting effects on population synchrony may be especially important as the climate changes because expected increases in environmental stochasticity add to the risk of global extinction when small population sizes are synchronized over large areas.

\section{INFLUENCE OF HARVESTING ON POPULATION STABILITY IN FLUCTUATING ENVIRONMENTS}

Theoretical modeling and empirical analyses have shown that both harvesting and environmental stochasticity induce population fluctuations and thus ultimately increase extinction risk (Lande et al. 1995, Fryxell et al. 2010). In addition, several lines of evidence have suggested that the combined effects of harvesting and environmental change can be synergistic, with greater extinction risk and faster population declines when both these stressors are present than what would be predicted from addition of the separate effects of each stressor (Mora et al. 2007, Fuller et al. 2015, Gamelon et al. 2019). In short, harvesting reduces the effective growth rate of populations, often making them less resilient to environmental fluctuations (Crespo \& Cao-García preprint https://arxiv.org/abs/2008.09398).

Harvesting that selectively targets certain groups of individuals can also amplify environmentally induced population fluctuations by biasing the population structure towards individuals that are more sensitive to environmental variation. This effect has been observed in multiple fish stocks (Hsieh et al. 2006, Shelton \& Mangel 2011, Rouyer et al. 2012). For example, in age-structured populations, removal of larger, older individuals through harvesting can lead to populations consisting mainly of smaller, younger individuals (Anderson et al. 2008), which often have higher natural mortality risk and lower reproductive rates (Berkeley et al. 2004). Offspring produced by younger individuals have also been shown to have lower survival potential than those from older individuals in some systems (Berkeley et al. 2004, Bobko $\&$ Berkeley 2004). Conversely, careful use of age-, sex- or size-selective harvesting can also help to stabilize populations. In ungulate population management, harvest strategies are often designed to target more calves and young individuals to maximize the mean annual yield or promote stability in population 
size and harvest over time (Sæther et al. 2001, Apollonio et al. 2010, Strand et al. 2012). Similarly, harvest restrictions and selective harvesting methods, such as gill nets in marine systems, could be utilized to promote recovery of natural size- and age structure after years of selective harvesting (Birkeland \& Dayton 2005).

Because effects of environmental stochasticity can depend on population density, leading to nonlinear responses in population growth (Royama 1992), population size reductions caused by harvesting may alter population stability through changes in densitydependent processes. Per capita resource availability and risk of disease transmission are examples of density-dependent factors where increasingly negative effects are typically observed at higher densities, and reduction in population size caused by harvest can then be compensated for by decreases in natural mortality or increases in reproductive output (Boyce et al. 1999). In certain cases, this can lead to a situation in which harvest mortality actually causes an increase in population size, sometimes called the 'hydra effect' (Abrams 2009). Density-dependent effects of environmental drivers have been found in many species where poor environmental conditions restrict access to resources (such as food or space) and lead to high intraspecific competition (Barbraud \& Weimerskirch 2003, Gamelon et al. 2017, Hansen et al. 2019). Population-level consequences of such nonlinear responses to the environment have recently been studied in Svalbard reindeer Rangifer tarandus platyrhynchus, where populations tend to crash when extreme winter climate events occur at high reindeer densities. Increased frequencies of such events due to global warming prevent overabundance and can therefore actually dampen population fluctuations because of a reduced risk of climate-induced starvation and population crashes (Hansen et al. 2019). Similarly, overabundance and population crashes can be avoided by population regulation through harvesting (McShea et al. 1997). Thus, while harvesting in some cases can amplify population fluctuations caused by environmental stochasticity (Gamelon et al. 2019), it can also reduce the density-dependent effects of harsh climatic conditions, thereby stabilizing population fluctuations and decreasing the risk of extinction (Peeters et al. preprint https://doi.org/10.22541/au.161311924.44472260/v1).

With more variable weather and greater environmental stochasticity predicted due to global warming (IPCC 2013), there is clearly an urgent need to better understand the relative contributions of climate forcing, harvesting and their interactions to popula- tion dynamics. Synergistic effects of environmental changes and harvest on population dynamics, and the complexity of indirect pathways through which they can influence populations, intensify the challenge of disentangling these effects. In addition, environmental changes and harvest can often have similar effects on populations, such as smaller body size being favored by both climate warming and harvest in many species (Gardner et al. 2011, Oke et al. 2020). This makes it particularly difficult to distinguish the effects of harvest from those of environmental variation and change, adding to the uncertainty of harvesting outcomes. The unclear distinction between different drivers calls for close collaboration between theoreticians, empiricists and managers. New theoretical harvesting models that incorporate both space and environmental fluctuations are being developed (Engen 2017, Engen et al. 2018a,b), creating opportunities to explore the combined impacts of different mechanisms. Empirical testing of results from such models is crucial to continued progress in this field.

\section{HARVESTING IN FLUCTUATING ENVIRONMENTS}

As shown in this paper, population responses to harvesting in fluctuating environments depend on a number of different factors, working through direct and indirect pathways. What does this mean for sustainable harvesting? Obviously, we cannot expect to fully understand all drivers of population dynamics and their interactions before we harvest, but awareness of effects such as those described here can help to identify potential issues before they arise, and also provide valuable opportunities to increase the sustainability of harvesting as the environment becomes more variable. One important question to consider is whether the target population shows strong population structure (e.g. age or stage structure) in vital rates, behavior or habitat use. If so, is the planned harvest scheme likely to influence this structure, and could something be done to minimize this effect? Second, what is the spatial structure of the population and is it linked to age or stage structure? What are the dispersal abilities and dispersal patterns of the population? Careful consideration of how the proposed harvest relates to the spatial structure and what dispersal might mean for responses to harvest are important. Establishment of no-take zones or adjusting quotas to account for hunter preferences and geographic bias are examples of measures that 
can be taken. If the planned harvest covers large extents of the spatial distribution of a species within a region, population synchrony should also be considered, keeping in mind that decreasing harvesting in low-abundance locations can help to avoid population synchronization. Particularly in cases where more than one species within an area are subject to harvest, multispecies harvesting models might be necessary to establish sustainable harvesting strategies. The development of multispecies or ecosystem models for fisheries has therefore become more common in recent years, although their use in practical management is still limited (Fogarty 2014, Säterberg et al. 2019). Because interspecific interactions can also influence responses to harvesting when only one species is harvested, it is worth keeping this possibility in mind when harvest strategies produce unexpected population responses. In specific cases where one or more of these issues come up, targeted modeling can be extremely useful to explore potential consequences of different harvesting strategies.

Clearly, sustainable harvesting in fluctuating environments depends on a thorough understanding of internal and external drivers of stochastic population dynamics. However, due to the range of factors that can influence population responses to harvest, their complex interactions and the amount of data required to estimate them, most harvesting decisions must be based on incomplete knowledge. One very useful framework for developing and adjusting harvesting strategies in this situation is adaptive management, in which the modeling that underlies a choice of harvest strategy is updated as data on population responses to the harvesting become available, leading to iteratively updated harvest strategies and increased knowledge of harvested systems (Walters \& Hilborn 1978, Johnson et al. 2015). Adaptive management of this type also supports sustainable harvesting in changing environments, since they allow strategies to be continuously adjusted as needed. In general, flexible and dynamic strategies and measures (such as dynamic protected areas; Cashion et al. 2020, Rassweiler et al. 2020) are likely to be necessary as the climate continues to warm and environments become more variable.

\section{CONCLUSIONS AND FUTURE PERSPECTIVES}

Spatial population structure, population synchrony and demographic structure are all characteristics of natural populations that can influence their resilience in the face of environmental fluctuations and change. As we have shown in this paper, harvesting can affect each of these characteristics in several, often unexpected or unintended, ways. Impacts of harvesting are not limited to the harvested populations, but can also influence non-harvested ones that are linked to the harvested populations through dispersal of individuals or interspecific interactions. In addition, interactions between different drivers of population dynamics, including harvesting, are likely common in nature. Thus, harvesting has the potential to elicit unexpected responses and leave populations more vulnerable to environmental fluctuations and climate change effects. However, knowledge of the different mechanisms and pathways involved can be used to minimize the negative effects of harvesting and improve its sustainability. Theoretical models play an important role in exploring and disentangling these pathways, and must be followed up by empirical tests of their results. Based on the research reviewed here, we believe 2 important priorities for the coming years should be to continue to clarify the relationship between harvesting and climate effects in different systems and situations, and to perform empirical tests of new theoretical results on harvestinduced synchrony, to see how common these mechanisms that could increase extinction risk are in natural systems. As our understanding of the mechanisms underlying population responses to harvesting continues to improve and the climate continues to warm, harvesting strategies that can be adjusted as our knowledge increases and as the environment changes can decrease the risk of driving populations to extinction through harvesting.

Acknowledgements. This work was supported by the Research Council of Norway (RCN; KLIMAFORSK project 244647 and SFF-III 223257/F50) and the Norwegian University of Science and Technology (NTNU). B.B.H. was additionally funded by RCN project 276080 . F.J.C.-G. was additionally funded by European Regional Development Fund (ERDF) and by the Spanish Ministry of Economy and Competitiveness through projects FIS2015-67765-R and RTI2018095802-B-I00, and by European Union's Horizon 2020 through grant agreement No. 817578 TRIATLAS.

\section{LITERATURE CITED}

Abrams PA (2009) When does greater mortality increase population size? The long history and diverse mechanisms underlying the hydra effect. Ecol Lett 12:462-474

Allee WC (1949) Principles of animal ecology. WB Saunders, Philadelphia, PA

Anderson CNK, Hsieh CH, Sandin SA, Hewitt R and others (2008) Why fishing magnifies fluctuations in fish abundance. Nature 452:835-839

Anderwald P, Herfindal I, Haller RM, Risch AC, Schütz M, Schweiger AK, Filli F (2015) Influence of migratory 
ungulate management on competitive interactions with resident species in a protected area. Ecosphere 6:art228 Apollonio M, Andersen R, Putman R (2010) European ungulates and their management in the $21^{\text {st }}$ century. Cambridge University Press, Cambridge

Barbraud C, Weimerskirch H (2003) Climate and density shape population dynamics of a marine top predator. Proc R Soc B 270:2111-2116

*Beddington JR (1974) Age structure, sex ratio and population density in the harvesting of natural animal populations. J Appl Ecol 11:915-924

* Beddington JR, May RM (1977) Harvesting natural populations in a randomly fluctuating environment. Science 197:463-465

Berkeley SA, Chapman C, Sogard SM (2004) Maternal age as a determinant of larval growth and survival in a marine fish, Sebastes melanops. Ecology 85:1258-1264

Birkeland C, Dayton PK (2005) The importance in fishery management of leaving the big ones. Trends Ecol Evol 20:356-358

Bobko SJ, Berkeley SA (2004) Maturity, ovarian cycle, fecundity, and age-specific parturition of black rockfish (Sebastes melanops). Fish Bull 102:418-429

Boukal DS, Bideault A, Carreira BM, Sentis A (2019) Species interactions under climate change: connecting kinetic effects of temperature on individuals to community dynamics. Curr Opin Insect Sci 35:88-95

Boyce MS, Sinclair ARE, White GC (1999) Seasonal compensation of predation and harvesting. Oikos 87:419-426

Brook BW, Whitehead PJ (2005) Sustainable harvest regimes for magpie geese (Anseranas semipalmata) under spatial and temporal heterogeneity. Wildl Res 32:459-464

* Brown JH, Kodricbrown A (1977) Turnover rates in insular biogeography - effect of immigration on extinction. Ecology 58:445-449

Bunnefeld N, Reuman DC, Baines D, Milner-Gulland EJ (2011) Impact of unintentional selective harvesting on the population dynamics of red grouse. J Anim Ecol 80: 1258-1268

* Burgess MG, Costello C, Fredston-Hermann A, Pinsky ML, Gaines SD, Tilman D, Polasky S (2017) Range contraction enables harvesting to extinction. Proc Natl Acad Sci USA 114:3945-3950

Cabral RB, Bradley D, Mayorga J, Goodell W and others (2020) A global network of marine protected areas for food. Proc Natl Acad Sci USA 117:28134-28139

* Campioni L, Lourenço R, Delgado MM, Penteriani V (2012) Breeders and floaters use different habitat cover: Should habitat use be a social status-dependent strategy? J Ornithol 153:1215-1223

* Cashion T, Nguyen T, ten Brink T, Mook A, PalaciosAbrantes J, Roberts SM (2020) Shifting seas, shifting boundaries: dynamic marine protected area designs for a changing climate. PLOS ONE 15:e0241771

* Chaverra A, Wieters E, Foggo A, Knights AM (2019) Removal of intertidal grazers by human harvesting leads to alteration of species interactions, community structure and resilience to climate change. Mar Environ Res 146:57-65

Chen IC, Hill JK, Ohlemüller R, Roy DB, Thomas CD (2011) Rapid range shifts of species associated with high levels of climate warming. Science 333:1024-1026

Costello C, Polasky S (2008) Optimal harvesting of stochastic spatial resources. J Environ Econ Manage 56:1-18

Coulson T (2001) Age, sex, density, winter weather, and population crashes in Soay sheep. Science 292:1528-1531
Dakos V, van Nes EH, Donangelo R, Fort H, Scheffer M (2010) Spatial correlation as leading indicator of catastrophic shifts. Theor Ecol 3:163-174

* den Boer PJ (1981) On the survival of populations in a heterogeneous and variable environment. Oecologia 50:39-53

Dennis B (2002) Allee effects in stochastic populations. Oikos 96:389-401

ํDennis B, Assas L, Elaydi S, Kwessi E, Livadiotis G (2016) Allee effects and resilience in stochastic populations. Theor Ecol 9:323-335

Dunn RP, Baskett ML, Hovel KA (2017) Interactive effects of predator and prey harvest on ecological resilience of rocky reefs. Ecol Appl 27:1718-1730

*Earn DJ, Levin SA, Rohani P (2000) Coherence and conservation. Science 290:1360-1364

*Edelhoff H, Zachos FE, Fickel J, Epps CW, Balkenhol N (2020) Genetic analysis of red deer (Cervus elaphus) administrative management units in a human-dominated landscape. Conserv Genet 21:261-276

*Edwards CTT, Plagányi ÉE (2011) Protecting old fish through spatial management: Is there a benefit for sustainable exploitation? J Appl Ecol 48:853-863

* Ellis RD, Powers JE (2012) Gag grouper, marine reserves, and density-dependent sex change in the Gulf of Mexico. Fish Res 115-116:89-98

Engen S (2017) Spatial synchrony and harvesting in fluctuating populations: relaxing the small noise assumption. Theor Popul Biol 116:18-26

Engen S, Lande R, Sæther BE (2002) The spatial scale of population fluctuations and quasi-extinction risk. Am Nat 160:439-451

* Engen S, Lande R, Sæther BE (2014) Evolutionary consequences of nonselective harvesting in density-dependent populations. Am Nat 184:714-726

* Engen S, Cao FJ, Sæther BE (2018a) The effect of harvesting on the spatial synchrony of population fluctuations. Theor Popul Biol 123:28-34

*Engen S, Lee AM, Sæther BE (2018b) Spatial distribution and optimal harvesting of an age-structured population in a fluctuating environment. Math Biosci 296:36-44

Estes JA, Duggins DO (1995) Sea otters and kelp forests in Alaska: generality and variation in a community ecological paradigm. Ecol Monogr 65:75-100

* Evans LC, Sibly RM, Thorbek P, Sims I, Oliver TH, Walters RJ (2019) Integrating the influence of weather into mechanistic models of butterfly movement. Mov Ecol 7:24

Fogarty MJ (2014) The art of ecosystem-based fishery management. Can J Fish Aquat Sci 71:479-490

Fogarty M, Botsford L (2007) Population connectivity and spatial management of marine fisheries. Oceanography 20:112-123

Frank KT, Petrie B, Leggett WC, Boyce DG (2016) Large scale, synchronous variability of marine fish populations driven by commercial exploitation. Proc Natl Acad Sci USA 113:8248-8253

Frank SC, Ordiz A, Gosselin J, Hertel A and others (2017) Indirect effects of bear hunting: a review from Scandinavia. Ursus 28:150-164

Fryxell JM, Packer C, McCann K, Solberg EJ, Sæther BE (2010) Resource management cycles and the sustainability of harvested wildlife populations. Science 328: 903-906

Fuller E, Brush E, Pinsky ML (2015) The persistence of populations facing climate shifts and harvest. Ecosphere 6: art153 
Gamelon M, Grøtan V, Nilsson ALK, Engen S and others (2017) Interactions between demography and environmental effects are important determinants of population dynamics. Sci Adv 3:e1602298

Gamelon M, Sandercock BK, Sæther BE (2019) Does harvesting amplify environmentally induced population fluctuations over time in marine and terrestrial species? J Appl Ecol 56:2186-2194

* Gardner JL, Peters A, Kearney MR, Joseph L, Heinsohn R (2011) Declining body size: a third universal response to warming? Trends Ecol Evol 26:285-291

* Gehr B, Hofer EJ, Pewsner M, Ryser A, Vimercati E, Vogt K, Keller LF (2018) Hunting-mediated predator facilitation and superadditive mortality in a European ungulate. Ecol Evol 8:109-119

Giometto A, Altermatt F, Rinaldo A (2017) Demographic stochasticity and resource autocorrelation control biological invasions in heterogeneous landscapes. Oikos 126: 1554-1563

Godsoe W, Murray R, Plank MJ (2015) The effect of competition on species' distributions depends on coexistence, rather than scale alone. Ecography 38:1071-1079

* Grüss A, Robinson J (2015) Fish populations forming transient spawning aggregations: Should spawners always be the targets of spatial protection efforts? ICES J Mar Sci 72:480-497

* Halpern BS (2003) The impact of marine reserves: Do reserves work and does reserve size matter? Ecol Appl 13:S117-S137

Hansen BB, Gamelon M, Albon SD, Lee AM and others (2019) More frequent extreme climate events stabilize reindeer population dynamics. Nat Commun 10:1616

Hansen BB, Grøtan V, Herfindal I, Lee AM (2020) The Moran effect revisited: spatial population synchrony under global warming. Ecography 43:1591-1602

*Haus JM, Webb SL, Strickland BK, McCarthy KP, Rogerson JE, Bowman JL (2020) Individual heterogeneity in resource selection has implications for mortality risk in white-tailed deer. Ecosphere 11:e03064

Hauser CE, Cooch EG, Lebreton JD (2006) Control of structured populations by harvest. Ecol Modell 196:462-470

* Haynes KJ, Liebhold AM, Fearer TM, Wang G, Norman GW, Johnson DM (2009) Spatial synchrony propagates through a forest food web via consumer-resource interactions. Ecology 90:2974-2983

Heino M, Kaitala V, Ranta E, Lindström J (1997) Synchronous dynamics and rates of extinction in spatially structured populations. Proc R Soc B 264:481-486

Heino M, Díaz Pauli B, Dieckmann U (2015) Fisheriesinduced evolution. Annu Rev Ecol Evol Syst 46:461-480

*Herrando-Pérez S, Delean S, Brook BW, Bradshaw CJA (2012) Strength of density feedback in census data increases from slow to fast life histories. Ecol Evol 2: 1922-1934

* Herrera-R GA, Oberdorff T, Anderson EP, Brosse S and others (2020) The combined effects of climate change and river fragmentation on the distribution of Andean Amazon fishes. Glob Change Biol 26:5509-5523

Hillyer R, Silman MR (2010) Changes in species interactions across a $2.5 \mathrm{~km}$ elevation gradient: effects on plant migration in response to climate change. Glob Change Biol 16:3205-3214

* Hsieh CH, Reiss CS, Hunter JR, Beddington JR, May RM, Sugihara G (2006) Fishing elevates variability in the abundance of exploited species. Nature 443:859-862
Hsieh CH, Reiss CS, Hewitt RP, Sugihara G (2008) Spatial analysis shows that fishing enhances the climatic sensitivity of marine fishes. Can J Fish Aquat Sci 65:947-961

*Hutchings JA (2005) Life history consequences of overexploitation to population recovery in Northwest Atlantic cod (Gadus morhua). Can J Fish Aquat Sci 62:824-832

* Ims RA (1990) The ecology and evolution of reproductive synchrony. Trends Ecol Evol 5:135-140

* Ims RA, Andreassen HP (2000) Spatial synchronization of vole population dynamics by predatory birds. Nature 408:194-196

IPCC (2013) Climate change 2013: the physical science basis. Contribution of Working Group I to the Fifth Assessment Report of the Intergovernmental Panel on Climate Change. Cambridge University Press, Cambridge

* Jarillo J, Sæther BE, Engen S, Cao FJ (2018) Spatial scales of population synchrony of two competing species: effects of harvesting and strength of competition. Oikos 127: 1459-1470

Jarillo J, Sæther BE, Engen S, Cao-García FJ (2020) Spatial scales of population synchrony in predator-prey systems. Am Nat 195:216-230

Jenkins DA, Lecomte N, Schaefer JA, Olsen SM and others (2016) Loss of connectivity among island-dwelling Peary caribou following sea ice decline. Biol Lett 12:20160235

Johnson FA, Boomer GS, Williams BK, Nichols JD, Case DJ (2015) Multilevel Learning in the adaptive management of waterfowl harvests: 20 years and counting. Wildl Soc Bull 39:9-19

Jonzen N, Ranta E, Lundberg P, Kaitala V, Lindén H (2003) Harvesting-induced population fluctuations? Wildl Biol 9:59-65

KKatsanevakis S, Stelzenmüller V, South A, Sørensen TK and others (2011) Ecosystem-based marine spatial management: review of concepts, policies, tools, and critical issues. Ocean Coast Manage 54:807-820

Kausrud KL, Viljugrein H, Frigessi A, Begon M and others (2007) Climatically driven synchrony of gerbil populations allows large-scale plague outbreaks. Proc R Soc B 274:1963-1969

Kent AD, Yannarell AC, Rusak JA, Triplett EW, McMahon KD (2007) Synchrony in aquatic microbial community dynamics. ISME J 1:38-47

*Kinzey D, Punt AE (2009) Multispecies and single-species models of fish population dynamics: comparing parameter estimates. Nat Resour Model 22:67-104

Koenig WD (2002) Global patterns of environmental synchrony and the Moran effect. Ecography 25:283-288

*Kumar R, Pitcher TJ, Varkey DA (2017) Ecosystem approach to fisheries: exploring environmental and trophic effects on maximum sustainable yield (MSY) reference point estimates. PLOS ONE 12:e0185575

Kuparinen A, Festa-Bianchet M (2017) Harvest-induced evolution: insights from aquatic and terrestrial systems. Philos Trans R Soc B 372:20160036

Kuussaari M, Saccheri I, Camara M, Hanski I (1998) Allee effect and population dynamics in the Glanville fritillary butterfly. Oikos 82:384-392

* Lande R, Engen S, Sæther BE (1995) Optimal harvesting of fluctuating populations with a risk of extinction. Am Nat 145:728-745

Kande R, Sæether BE, Engen S (1997) Threshold harvesting for sustainability of fluctuating resources. Ecology 78 : 1341-1350 
Lande R, Engen S, Sæther BE (1998) Extinction times in finite metapopulation models with stochastic local dynamics. Oikos 83:383-389

Lande R, Engen S, Sæther BE (1999) Spatial scale of population synchrony: environmental correlation versus dispersal and density regulation. Am Nat 154:271-281

Kangvatn R, Loison A (1999) Consequences of harvesting on age structure, sex ratio and population dynamics of red deer Cervus elaphus in central Norway. Wildl Biol 5: 213-223

Kaw R, Plank MJ, Kolding J (2016) Balanced exploitation and coexistence of interacting, size-structured, fish species. Fish Fish 17:281-302

* Le Moullec M, Pedersen ÅØ, Stien A, Rosvold J, Hansen BB (2019) A century of conservation: the ongoing recovery of Svalbard reindeer. J Wildl Manag 83:1676-1686

Lee AM, Sæther BE, Engen S (2020) Spatial covariation of competing species in a fluctuating environment. Ecology 101:e02901

Lefebvre J, Gauthier G, Giroux JF, Reed A, Reed ET, Bélanger L (2017) The greater snow goose Anser caerulescens atlanticus: managing an overabundant population. Ambio 46(Suppl 2):S262-S274

*egović T, Geček S (2010) Impact of maximum sustainable yield on independent populations. Ecol Modell 221: 2108-2111

* Legović T, Klanjšček J, Geček S (2010) Maximum sustainable yield and species extinction in ecosystems. Ecol Modell 221:1569-1574

Levin PS, Fogarty MJ, Murawski SA, Fluharty D (2009) Integrated ecosystem assessments: developing the scientific basis for ecosystem-based management of the ocean. PLOS Biol 7:e100004

KLiebhold A, Koenig WD, Bjørnstad ON (2004) Spatial synchrony in population dynamics. Annu Rev Ecol Evol Syst 35:467-490

* Loe LE, Irvine RJ, Bonenfant C, Stien A and others (2006) Testing five hypotheses of sexual segregation in an Arctic ungulate. J Anim Ecol 75:485-496

K Lord JP, Barry JP, Graves D (2017) Impact of climate change on direct and indirect species interactions. Mar Ecol Prog Ser 571:1-11

Marquez JF, Lee AM, Aanes S, Engen S, Herfindal I, Salthaug A, Sæther BE (2019) Spatial scaling of population synchrony in marine fish depends on their life history. Ecol Lett 22:1787-1796

May RM, Beddington JR, Horwood JW, Shepherd JG (1978) Exploiting natural populations in an uncertain world. Math Biosci 42:219-252

* McCullough DR (1996) Spatially structured populations and harvest theory. J Wildl Manag 60:1-9

McShea WJ, Underwood HB, Rappole JH (eds) (1997) The science of overabundance: deer ecology and population management. Smithsonian Institution Press, Washington, DC

Milner JM, Nilsen EB, Andreassen HP (2007) Demographic side effects of selective hunting in ungulates and carnivores. Conserv Biol 21:36-47

* Mockrin MH, Redford KH (2011) Potential for spatial management of hunted mammal populations in tropical forests. Conserv Lett 4:255-263

Moland E, Olsen EM, Knutsen H, Garrigou P and others (2013) Lobster and cod benefit from small-scale northern marine protected areas: inference from an empirical before-after control-impact study. Proc R Soc B 280:20122679
Monzón J, Moyer-Horner L, Palamar MB (2011) Climate change and species range dynamics in protected areas. Bioscience 61:752-761

Mora C, Metzger R, Rollo A, Myers RA (2007) Experimental simulations about the effects of overexploitation and habitat fragmentation on populations facing environmental warming. Proc R Soc B 274:1023-1028

Moran PAP (1953) The statistical analysis of the Canadian lynx cycle. 2. Synchronization and meteorology. Aust J Zool 1:291-298

Morita K, Fukuwaka M, Tanimata N (2010) Age-related thermal habitat use by Pacific salmon Oncorhynchus spp. J Fish Biol 77:1024-1029

Morrongiello JR, Horn PL, Ó Maolagáin C, Sutton PJH (2021) Synergistic effects of harvest and climate drive synchronous somatic growth within key New Zealand fisheries. Glob Change Biol 27:1470-1484

*Mourier J, Mills SC, Planes S (2013) Population structure, spatial distribution and life-history traits of blacktip reef sharks Carcharhinus melanopterus. J Fish Biol 82: 979-993

* Munday PL, Leis JM, Lough JM, Paris CB, Kingsford MJ, Berumen ML, Lambrechts J (2009) Climate change and coral reef connectivity. Coral Reefs 28:379-395

* Naranjo EJ, Bodmer RE (2007) Source-sink systems and conservation of hunted ungulates in the Lacandon Forest, Mexico. Biol Conserv 138:412-420

Neubert MG (2003) Marine reserves and optimal harvesting. Ecol Lett 6:843-849

* Novaro AJ, Funes MC, Walker RS (2005) An empirical test of source-sink dynamics induced by hunting. J Appl Ecol 42:910-920

\% Ofstad EG, Markussen SS, Sæther BE, Solberg EJ and others (2020) Opposing fitness consequences of habitat use in a harvested moose population. J Anim Ecol 89: 1701-1710

\% Oke KB, Cunningham CJ, Westley PAH, Baskett ML and others (2020) Recent declines in salmon body size impact ecosystems and fisheries. Nat Commun 11:4155

Pauly D, Christensen V, Dalsgaard J, Froese R, Torres F Jr (1998) Fishing down marine food webs. Science 279: 860-863

* Peeters B, Le Moullec M, Raeymaekers JAM, Marquez JF and others (2020) Sea ice loss increases genetic isolation in a high Arctic ungulate metapopulation. Glob Chang Biol 26:2028-2041

* Peeters B, Pedersen А̊Ø, Veiberg V, Hansen BB (2021) Hunting quotas, selectivity and stochastic population dynamics challenge the management of wild reindeer. Clim Res (in press), doi:10.3354/cr01668

* Péron G, Ferrand Y, Choquet R, Pradel R and others (2012) Spatial heterogeneity in mortality and its impact on the population dynamics of Eurasian woodcocks. Popul Ecol 54:305-312

Plagányi ÉE (2007) Models for an ecosystem approach to fisheries. FAO Fisheries Technical Paper No. 477. FAO, Rome

* Plagányi ÉE, Punt AE, Hillary R, Morello EB and others (2014) Multispecies fisheries management and conservation: tactical applications using models of intermediate complexity. Fish Fish 15:1-22

* Planque B, Fromentin JM, Cury P, Drinkwater KF, Jennings S, Perry RI, Kifani S (2010) How does fishing alter marine populations and ecosystems sensitivity to climate? J Mar Syst 79:403-417 
Planque B, Loots C, Petitgas P, Lindstrom U, Vaz S (2011) Understanding what controls the spatial distribution of fish populations using a multi-model approach. Fish Oceanogr 20:1-17

Poisson Y, Festa-Bianchet M, Pelletier F, Toit J (2020) Testing the importance of harvest refuges for phenotypic rescue of trophy-hunted populations. J Appl Ecol 57:526-535

Ranta E, Lundberg P, Kaitala V (2006) Ecology of populations. Cambridge University Press, Cambridge

Rassweiler A, Ojea E, Costello C (2020) Strategically designed marine reserve networks are robust to climate change driven shifts in population connectivity. Environ Res Lett 15:034030

Ripa J, Ranta E (2007) Biological filtering of correlated environments: towards a generalised Moran theorem. Oikos 116:783-792

Rodrigues AMM, Johnstone RA (2014) Evolution of positive and negative density-dependent dispersal. Proc R Soc B 281:20141226

Rouyer T, Sadykov A, Ohlberger J, Stenseth NC (2012) Does increasing mortality change the response of fish populations to environmental fluctuations? Ecol Lett 15: 658-665

Royama T (1992) Analytical population dynamics. Springer, Dordrecht

Sæther BE (1997) Environmental stochasticity and population dynamics of large herbivores: a search for mechanisms. Trends Ecol Evol 12:143-149

Sæther BE, Bakke O (2000) Avian life history variation and contribution of demographic traits to the population growth rate. Ecology 81:642-653

Sæther BE, Engen S (2002) Pattern of variation in avian population growth rates. Philos Trans R Soc B 357:1185-1195

Sæther BE, Engen S, Lande R, Saether BE (1996) Densitydependence and optimal harvesting of fluctuating populations. Oikos 76:40-46

Sæather BE, Engen S, Solberg EJ (2001) Optimal harvest of age-structured populations of moose Alces alces in a fluctuating environment. Wildl Biol 7:171-179

Sæther BE, Solberg EJ, Heim M (2003) Effects of altering sex ratio structure on the demography of an isolated moose population. J Wildl Manag 67:455-466

Säterberg T, Casini M, Gårdmark A (2019) Ecologically sustainable exploitation rates - a multispecies approach for fisheries management. Fish Fish 20:952-961

Schaefer M (1991) Some aspects of the dynamics of populations important to the management of the commercial marine fisheries. Bull Math Biol 53:253-279

Shelton AO, Mangel M (2011) Fluctuations of fish populations and the magnifying effects of fishing. Proc Natl Acad Sci USA 108:7075-7080

Editorial responsibility: Nils Bunnefeld (Guest Editor), Stirling, UK

Reviewed by: 2 anonymous referees
Silliman BR, Angelini C (2012) Trophic cascades across diverse plant ecosystems. Nat Educ Knowl 3:44

* Smith ADM, Brown CJ, Bulman CM, Fulton EA and others (2011) Impacts of fishing low-trophic level species on marine ecosystems. Science 333:1147-1150

Stoner DC, Wolfe ML, Choate DM (2006) Cougar exploitation levels in Utah: implications for demographic structure, population recovery, and metapopulation dynamics. J Wildl Manag 70:1588-1600

Strand O, Nilsen EB, Solberg EJ, Linnell JCD (2012) Can management regulate the population size of wild reindeer (Rangifer tarandus) through harvest? Can J Zool 90: 163-171

Stubberud MW, Vindenes Y, Vøllestad LA, Winfield IJ, Stenseth NC, Langangen $\varnothing$ (2019) Effects of size- and sex-selective harvesting: an integral projection model approach. Ecol Evol 9:12556-12570

* Swain DP, Sinclair AF, Hanson JM (2007) Evolutionary response to size-selective mortality in an exploited fish population. Proc R Soc B 274:1015-1022

* Thorpe RB (2019) What is multispecies MSY? A worked example from the North Sea. J Fish Biol 94:1011-1018

Tromeur E, Doyen L (2019) Optimal harvesting policies threaten biodiversity in mixed fisheries. Environ Model Assess 24:387-403

Tuljapurkar SD (1982) Population dynamics in variable environments. III. Evolutionary dynamics of $r$-selection. Theor Popul Biol 21:141-165

Turgeon K, Kramer DL (2012) Compensatory immigration depends on adjacent population size and habitat quality but not on landscape connectivity. J Anim Ecol 81:1161-1170

*Urban MC, Zarnetske PL, Skelly DK (2013) Moving forward: dispersal and species interactions determine biotic responses to climate change. Ann NY Acad Sci 1297:44-60

* VanDerWal J, Murphy HT, Kutt AS, Perkins GC, Bateman BL, Perry JJ, Reside AE (2013) Focus on poleward shifts in species' distribution underestimates the fingerprint of climate change. Nat Clim Chang 3:239-243

*Venturelli PA, Shuter BJ, Murphy CA (2009) Evidence for harvest-induced maternal influences on the reproductive rates of fish populations. Proc R Soc B 276:919-924

* Volterra V (1928) Variations and fluctuations of the number of individuals in animal species living together. ICES J Mar Sci 3:3-51

*Walter JA, Sheppard LW, Anderson TL, Kastens JH, Bjørnstad ON, Liebhold AM, Reuman DC (2017) The geography of spatial synchrony. Ecol Lett 20:801-814

* Walters CJ, Hilborn R (1978) Ecological optimization and adaptive management. Annu Rev Ecol Syst 9:157-188

* Weisberg M, Reisman K (2008) The robust Volterra principle. Philos Sci 75:106-131

Submitted: September 17, 2020

Accepted: April 23, 2021

Proofs received from author(s): August 29, 2021 